\title{
Underwater vs conventional endoscopic mucosal resection in the management of colorectal polyps: a systematic review and meta- analysis
}

\section{(ㄷ)(우우}

Authors

Faisal Kamal ${ }^{1}$, Muhammad Ali Khan ${ }^{2}$, Wade Lee-Smith ${ }^{3}$, Zubair Khan ${ }^{4}$, Sachit Sharma ${ }^{5}$, Claudio Tombazzi ${ }^{1}$, Dina Ahmad', Mohammad Kashif Ismail', Colin W. Howden¹, Kenneth F. Binmoeller ${ }^{6}$

Institutions

1 Division of Gastroenterology, University of Tennessee Health Science Center, Memphis, Tennessee, United States

2 Division of Gastroenterology, University of Alabama at Birmingham, Birmingham, Alabama, United States

3 Carlson and Mulford Libraries, University of Toledo, Ohio, United States

4 Division of Gastroenterology, University of Texas Houston, Houston, Texas, United States

5 Division of Internal Medicine, University of Toledo, Ohio, United States

6 Division of Gastroenterology, California Pacific Medical Center, San Francisco, California, United States

submitted 28.2.2020

accepted after revision $\quad 25.5 .2020$

Bibliography

Endoscopy International Open 2020; 08: E1264-E1272

DOI 10.1055/a-1214-5692

ISSN 2364-3722

(c) 2020. The Author(s).

This is an open access article published by Thieme under the terms of the Creative Commons Attribution-NonDerivative-NonCommercial License, permitting copying and reproduction so long as the original work is given appropriate credit. Contents may not be used for commecial purposes, or adapted, remixed, transformed or built upon. (https://creativecommons.org/licenses/by-nc-nd/4.0/)

Corresponding author

Faisal Kamal, MD, Division of Gastroenterology and Hepatology, University of Tennessee Health Sciences Center, 956 Court Avenue, Suite H314C, Memphis, TN, 38163

Fax: +1-901-448-7836

fkamal36@gmail.com

\# Supplementary material is available under https://doi.org/10.1055/a-1214-5692
ABSTRACT

Background Recently, underwater endoscopic mucosal resection (UEMR) has shown promising results in the management of colorectal polyps. Some studies have shown better outcomes compared to conventional endoscopic mucosal resection (EMR). We conducted this systematic review and meta-analysis to compare UEMR and EMR in the management of colorectal polyps.

Methods We searched several databases from inception to November 2019 to identify studies comparing UEMR and EMR. Outcomes assessed included rates of en bloc resection, complete macroscopic resection, recurrent/residual polyps on follow-up colonoscopy, complete resection confirmed by histology and adverse events. Pooled risk ratios (RR) with $95 \%$ confidence interval were calculated using a fixed effect model. Heterogeneity was assessed by $I^{2}$ statistic. Funnel plots and Egger's test were used to assess publication bias. We used the Newcastle-Ottawa scale (NOS) for assessment of quality of observational studies, and the Cochrane tool for assessing risk of bias for RCTs

Results Seven studies with 1291 patients were included; two were randomized controlled trials and five were observational. UEMR demonstrated statistically significantly better efficacy in rates of en bloc resection, pooled RR 1.16 $(1.08,1.26)$, complete macroscopic resection, pooled $R R$ 1.28 (1.18, 1.39), recurrent/residual polyps; pooled RR $0.26(0.12,0.56)$ and complete resection confirmed by histology; pooled RR $0.75(0.57,0.98)$. There was no significant difference in adverse events (AEs); pooled RR 0.68 (0.44, 1.05).

Conclusions This meta-analysis found statistically significantly better rates of en bloc resection, complete macroscopic resection, and lower risk of recurrent/residual polyps with UEMR compared to EMR. We found no significant difference in AEs between the two techniques. 


\section{Introduction}

Removal of adenomatous polyps during colonoscopy decreases the risk of death from colorectal cancer [1]. Endoscopic mucosal resection (EMR) is an effective modality for removal of large and sessile/flat polyps. Endoscopic submucosal dissection (ESD) and surgery are potential alternatives to EMR. En bloc resection rate is better with ESD compared to EMR but ESD is associated with increased risk of perforation and requires a higher level of expertise [2]. Surgery for colorectal polyps is associated with higher risks of morbidity and mortality and increased costs compared to EMR [3,4].

Conventional endoscopic mucosal resection (EMR) with submucosal injection and after insufflating the colon with air or carbon dioxide is currently the most commonly performed EMR technique. Underwater endoscopic mucosal resection (UEMR) is a newer alternative to EMR for removal of large sessile colorectal polyps [5]. Initially reported in 2012, it has since shown promising results. UEMR is performed by suctioning out gas from the colonic lumen and instilling water immediately before polyp resection [6]. Filling the colon lumen with water instead of gas decreases wall tension and has a buoyancy effect on the mucosa and submucosa raising them above the muscularis layer without the need for submucosal injection [7]. This changes the borders and shape of a lesion, potentially making it easier to resect completely with snaring. A recent meta-analysis evaluating the efficacy of UEMR reported a complete resection rate of $96 \%$ and an en bloc resection rate of $57 \%$ [8]; however, this analysis was confined to single-arm non-comparative studies. UEMR has also shown better results compared to EMR in the management of recurrent polyps after prior piecemeal EMR [9]. These polyps are often difficult to resect en bloc due to fibrosis from prior attempts at polyp resection. Studies comparing EMR and UEMR have reported conflicting results. Therefore, we conducted a systematic review and meta-analysis to compare UEMR and EMR for resection of flat and sessile colorectal polyps.

\section{Methods}

\section{Data sources and search strategy}

We followed the Preferred Reporting items for Systematic Review and Meta-Analysis (PRISMA) guidelines to conduct this systematic review and meta-analysis [10]. We performed a comprehensive search of several databases including MEDLINE using the PubMed interface (1950-present), Embase (1947present), Web of Science Core Collection (1965-present), and Cochrane Register of Controlled Trails (1966-present) from inception through 11/12/2019. The search strategy was designed by study investigators (F.K. and Z.K.) and was refined and conducted by an experience medical librarian (W.L.-S.) using keywords and controlled vocabularies (MeSH and Emtree headings) for the topics of endoscopic mucosal resection, underwater, polyps, and colon. A sample search is included from Embase in Appendix A. There was no limitation of language in conducting the search. Publication types of editorial, guidelines, case reports, and reviews were excluded when possible. The key-
139 articles identified from database search

61 articles removed as duplicates

78 articles screened after duplicates removal

43 articles excluded after title and abstract review

35 articles from database search reviewed

3 records identified by backward snowballing

38 full text articles assessed for eligibility

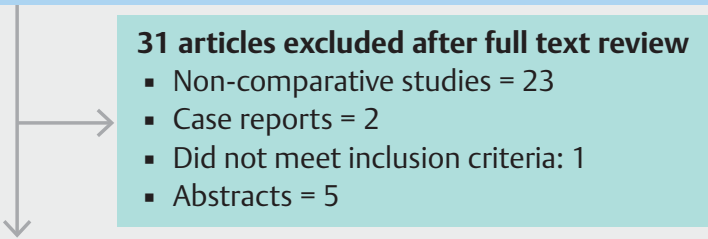

7 studies included in meta-analysis

- 2 randomized controlled trials

- 5 observational studies

- Fig. 1 PRISMA flowchart. From: Moher D, Liberati A, Tetzlaff J, Altman DG, The PRISMA Group (2009). Preferred Reporting Items for Systematic Reviews and Meta-Analyses: The PRISMA Statement. PLoS Med 6 (7): e1000097. doi:10.1371/journal.pmed1000097

words used in search included "Endoscopic-mucosal-resection" OR "EMR" OR "endoscopic-aspiration-mucosectomy" OR "endoscopic-mucosa-resection" OR endoscopic-mucosectomy” OR "endoscopic mucosal resection" AND "water" OR "underwater" OR "UEMR" OR “U-EMR" OR "water" AND "polyp” OR "polyps" OR "polypoid-lesion” AND "colon” OR "colorectal” OR “colonic" OR "rectum" OR "rectal” OR “colonic-neoplasm” OR 'intestine polyp'/exp.

Two authors (F.K. and M.A.K.) independently reviewed the titles and abstracts of studies retrieved from the search to identify those that fulfilled inclusion criteria. To maximize the yield of the search, the reference lists of identified studies were also reviewed to identify any additional relevant studies. Search strategy is illustrated in > Fig. 1.

Two authors (F.K. and M.A.K.) searched for observational studies and randomized controlled trials (RCTs) comparing the efficacy and/or safety of UEMR and EMR for resection of sessile colorectal polyps. Non-comparative studies and studies with patients $<18$ years of age or with animal data were excluded. All articles were downloaded into Endnote 7.0, a bibliographic database manager. Duplicate citations were removed. We included both fully published studies and abstracts.

\section{Outcomes of interest and inclusion criteria}

The outcomes of interest included rates of en bloc resection, complete macroscopic resection (defined by complete endoscopic resection of polyp with absence of any macroscopically 
visible polyp fragments on endoscopic views at the end of resection), recurrent or residual polyps on follow-up colonoscopy, complete resection confirmed by histology, and adverse events (AEs). Regarding the outcome of "complete resection confirmed by histology", two studies reported data as R0 resection defined as en bloc resection with histologically confirmed negative margins $[11,12]$. One study reported data on incomplete resection rate based on pathologic assessment of biopsies from the resection margin of polyps [13]. Incomplete resection was defined as the presence of any adenomatous or serrated pathology in the resection margin. We assumed that the rest of the polyps had been completely resected and confirmed by histology.

Our analysis only included sessile and flat polyps $\geq 10 \mathrm{~mm}$ that were resected using UEMR. We excluded pedunculated polyps that were resected underwater. Sessile or pedunculated polyps $<10 \mathrm{~mm}$ resected underwater were also excluded.

\section{Data extraction}

Two authors (F.K. and S.S.) assessed the eligibility of selected studies and extracted data using data extraction forms specifically designed for this study. Any disagreement between the authors was discussed with a third author (K.F.B.) and agreement was reached by consensus. Extracted data included study design, year and country of publication, patient demographics, inclusion criteria, exclusion criteria and - for each group - rates of en bloc resection, piecemeal resection, complete macroscopic resection, recurrent/residual polyps on follow-up colonoscopy, as well as resection times of polyps and AEs ( $\downarrow$ Table 1 and $>$ Table 2).

\section{Statistical analysis}

Data were analyzed using a fixed effect model and summarized as pooled risk ratio (RR) with $95 \%$ confidence interval $(\mathrm{Cl}) . P<$ 0.05 was considered statistically significant. $P<0.1$ for Cochran Q test or an $I^{2}>50 \%$ indicated significant heterogeneity. Publication bias was assessed using funnel plots and Egger's test. When publication bias was detected, Duval and Tweedie's trim and fill test was used to report adjusted effect size. All statistical analyses were performed using Review Manager (RevMan, version 5.3 for Windows; The Cochrane Collaboration, The Nordic Cochrane Centre, Copenhagen, Denmark, 2014).

Predetermined subgroup analyses were conducted to evaluate randomized controlled trials (RCTs) separately from observational studies. Sensitivity analyses were performed based on inclusion and exclusion of outlier studies where the study population differed substantially from other studies to explain heterogeneity. One study [9] was considered to be an outlier. It compared UEMR and EMR in the management of recurrent polyps after prior attempts at resection. Additionally, some polyps in that study might have been $<10 \mathrm{~mm}$, although most were $>10 \mathrm{~mm}$; median polyp sizes were $12 \mathrm{~mm}$ and $14 \mathrm{~mm}$ in the UEMR and EMR groups, respectively.

\section{Results}

\section{Search strategy yield and quality assessment}

The search strategy yielded 139 articles, of which 61 were removed as duplicates. Of the remaining 78 studies, 43 were excluded after title and abstract review. Bibliographic review of the remaining 35 revealed three additional studies. Therefore, 38 articles underwent full text review. Finally, seven studies [9,11-16] with 1291 patients met our inclusion criteria and were included in analysis. 537 polyps were removed by UEMR and 568 by EMR. Two studies $[11,13]$ were RCTs; the remaining five were observational $[9,12,14-16]$. $>$ Table 1 summarizes the characteristics of included studies. Table 2 summarizes data of outcomes of interest. Cadoni et al [12] had also presented data on pedunculated polyps which we did not include in our analysis.

\section{Quality assessment}

We used the Newcastle-Ottawa scale (NOS) for assessment of methodological quality of observational studies, and the Cochrane tool for assessing risk of bias for RCTs. The Cochrane tool assesses the presence of selection bias by evaluating the methods of randomization and allocation concealment; performance and detection of biases by checking for blinding of personnel and outcome assessment, respectively; attrition and reporting bias by evaluating for incomplete and selective reporting of data, respectively. In the RCTs included in our metaanalysis, the blinding of endoscopists to treatment allocation was not possible. Therefore, all RCTs had high risk of performance bias. However, all RCTs had low risk of selection, detection, attrition and reporting biases. The risk of bias assessment of RCTs is summarized in Supplementary Table 1.

NOS measures quality in the three parameters of selection, comparability and outcome, and allocates a maximum of 4, 2, and 3 points to each, respectively. High-quality studies score more than 7, moderate-quality studies score between 5 and 7 and low-quality studies score less than 5 on this scale. Four observational studies included in our analysis were of high quality and one study was of moderate quality. The quality assessment of observational studies is summarized in Supplementary Table 2. Two authors (F.K. and M.A.K.) independently performed the quality assessment and any disagreement was discussed with a third author (C.W.H.).

\section{Meta-analysis}

En bloc resection

Six studies $[9,11-13,15,16]$ reported data on en bloc resection for 464 polyps removed by UEMR and 506 by EMR. Rates with UEMR and EMR were $77 \%$ and $63 \%$, respectively. We found that the rate of en bloc resection was significantly higher (better) with UEMR compared to EMR; Pooled RR (95\% CI) 1.16 (1.08, 1.26), Cochran $Q$ test $P=0.08, I^{2}=49 \%$ ( $>$ Fig. 2a). No publication bias was detected based on funnel plot (Supplementary Fig.A). Subgroup analysis confined to RCTs still showed statistically significant higher en bloc resection rate with UEMR; pooled RR $(95 \% \mathrm{CI}) 1.16(1.03,1.31), \mathrm{I}^{2}=0 \%$. Sub- 
- Table 1 Characteristics of included studies.

\begin{tabular}{|c|c|c|c|c|c|c|c|}
\hline $\begin{array}{l}\text { Study, } \\
\text { year }\end{array}$ & $\begin{array}{l}\text { Country, } \\
\text { Single vs } \\
\text { multicen- } \\
\text { ter }\end{array}$ & Type of study & $\begin{array}{l}\text { Total } \\
\text { num- } \\
\text { ber } \\
\text { of pa- } \\
\text { tients }\end{array}$ & Males & $\begin{array}{l}\text { Number } \\
\text { of op- } \\
\text { erators }\end{array}$ & Inclusion criteria & Exclusion criteria \\
\hline $\begin{array}{l}\text { Schenck } \\
\text { et al, } \\
2017\end{array}$ & $\begin{array}{l}\text { USA, Single } \\
\text { center }\end{array}$ & $\begin{array}{l}\text { Retrospective, } \\
\text { cohort }\end{array}$ & 99 & 62 & NR & $\begin{array}{l}\text { Patients who had EMR or } \\
\text { UEMR of a polyp } \geq 15 \mathrm{~mm} \text { in } \\
\text { the colon or rectum, which } \\
\text { had not undergone prior at- } \\
\text { tempted endoscopic resec- } \\
\text { tion. }\end{array}$ & NR \\
\hline $\begin{array}{l}\text { Cadoni } \\
\text { et al, } \\
2017\end{array}$ & $\begin{array}{l}\text { Italy, Tai- } \\
\text { wan, UK, } \\
\text { Multicen- } \\
\text { ter }\end{array}$ & $\begin{array}{l}\text { Retrospective, } \\
\text { cohort }\end{array}$ & 287 & 190 & 4 & $\begin{array}{l}\text { Patients }>18 \text { years who un- } \\
\text { derwent colonoscopy from } \\
\text { January } 2015 \text { - December } \\
2016 \text { with polypectomy. Ses- } \\
\text { sile, flat and pedunculated } \\
\text { polyps } \geq 6 \text { mm removed by } \\
\text { hot snare either using gas in- } \\
\text { sufflation polypectomy (GIP) } \\
\text { and submucosal injection or } \\
\text { underwater. }\end{array}$ & NR \\
\hline $\begin{array}{l}\text { Yama- } \\
\text { shina et } \\
\text { al, } 2019\end{array}$ & $\begin{array}{l}\text { Japan, Mul- } \\
\text { ticenter }\end{array}$ & RCT & 210 & 139 & 28 & $\begin{array}{l}\text { Patients } \geq 20 \text { years undergo- } \\
\text { ing endoscopic resection for } \\
\text { colorectal mucosal lesions } \\
\text { that were } 10-20 \mathrm{~mm} \text { in } \\
\text { diameter }\end{array}$ & $\begin{array}{l}\text { Pedunculated lesions; resi- } \\
\text { dual lesions after endoscopic } \\
\text { resection; and lesions in pa- } \\
\text { tients with inflammatory } \\
\text { bowel disease, familial poly- } \\
\text { posis, electrolyte abnormali- } \\
\text { ty, coagulopathy, or severe } \\
\text { organ failure }\end{array}$ \\
\hline $\begin{array}{l}\text { Kim et } \\
\text { al, } 2014\end{array}$ & $\begin{array}{l}\text { USA, Single } \\
\text { center }\end{array}$ & $\begin{array}{l}\text { Retrospective } \\
\text { cross-sectional }\end{array}$ & 80 & 50 & 1 & $\begin{array}{l}\text { Patients referred to an inter- } \\
\text { ventional colonoscopy clinic } \\
\text { for recurrence after piece- } \\
\text { meal EMR of colorectal later- } \\
\text { ally spreading tumors (LSTs) }\end{array}$ & $\begin{array}{l}\text { Lesions smaller than } 8 \mathrm{~mm} \\
\text { were excluded }\end{array}$ \\
\hline $\begin{array}{l}\text { Yen et } \\
\text { al, } 2019\end{array}$ & $\begin{array}{l}\text { USA, Multi- } \\
\text { center }\end{array}$ & RCT & 255 & 248 & 1 & $\begin{array}{l}\text { All } \geq 18 \text { years old patients } \\
\text { scheduled for outpatient co- } \\
\text { lonoscopy, Polyps }>5 \mathrm{~mm} \text { in } \\
\text { size }\end{array}$ & $\begin{array}{l}\text { Hospitalized patients, un- } \\
\text { interrupted antithrombotic } \\
\text { therapy at the time of colo- } \\
\text { noscopy, uncorrected coa- } \\
\text { gulopathy (INR }>1.5 \text { ) or } \\
\text { thrombocytopenia (platelet } \\
\text { count }<50,000 \text { ), significant } \\
\text { comorbidities ASA classifica- } \\
\text { tion } \geq 4 \text {, diminutive ( }<5 \mathrm{~mm} \text { ) } \\
\text { polyps, pedunculated le- } \\
\text { sions, lesions with endo- } \\
\text { scopic evidence of deep sub- } \\
\text { mucosal invasion. }\end{array}$ \\
\hline $\begin{array}{l}\text { Rodri- } \\
\text { guez- } \\
\text { San- } \\
\text { chez et } \\
\text { al, } 2019\end{array}$ & $\begin{array}{l}\text { Spain, Mul- } \\
\text { ticenter }\end{array}$ & $\begin{array}{l}\text { Prospective } \\
\text { cross-sectional }\end{array}$ & 137 & NR & 2 & $\begin{array}{l}\text { All colorectal endoscopic re- } \\
\text { sections of lesions }>15 \mathrm{~mm} \\
\text { performed with both tech- } \\
\text { niques (UEMR and CEMR) } \\
\text { were included. }\end{array}$ & NR \\
\hline $\begin{array}{l}\text { Chien et } \\
\text { al, } 2019\end{array}$ & $\begin{array}{l}\text { USA, Japan, } \\
\text { Taiwan, } \\
\text { Multicen- } \\
\text { ter }\end{array}$ & $\begin{array}{l}\text { Retrospective } \\
\text { cohort }\end{array}$ & 223 & NR & 1 & $\begin{array}{l}\text { Age } \geq 20 \text { years, medium to } \\
\text { large lesions ( } \geq 10 \mathrm{~mm} \text { ) with } \\
\text { Paris classification } 0 \text {-Is, Ila, or } \\
\text { Ilc morphology }\end{array}$ & NR \\
\hline
\end{tabular}

RCT, randomized controlled trial; NR, not reported; UEMR, underwater endoscopic mucosal resection; ASA, American Society of Anesthesiologist; CEMR; conventional endoscopic mucosal resection 


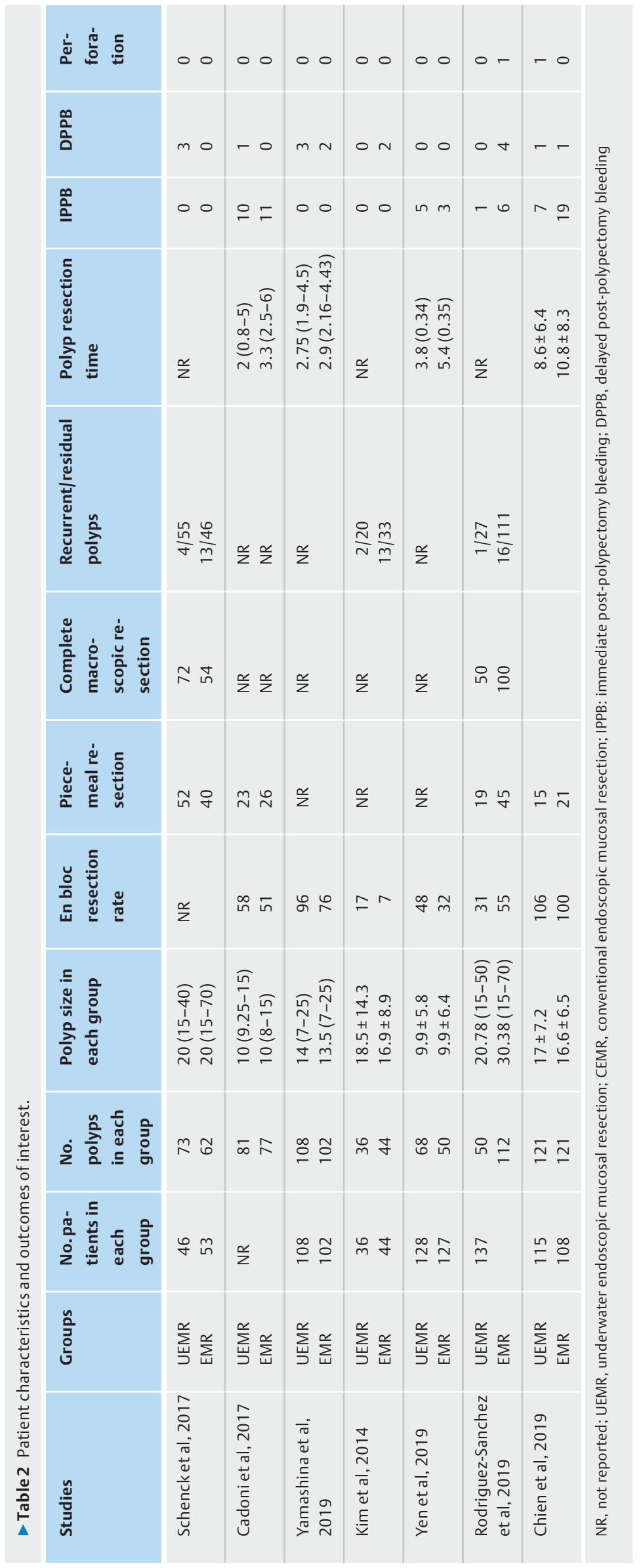




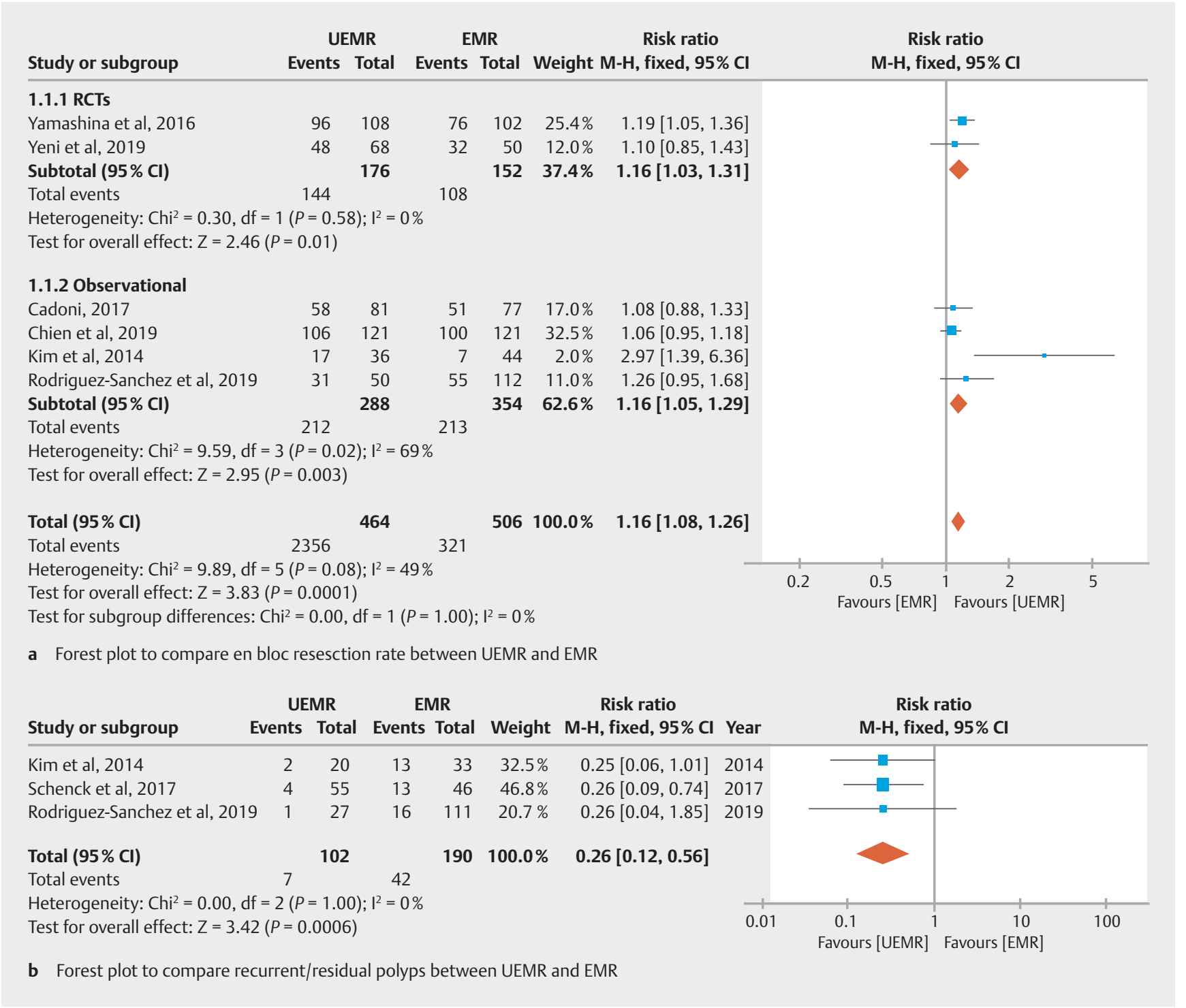

- Fig. 2 Forest plot to compare en bloc resection rate and recurrent/residual polyps between UEMR and EMR.

group analysis including observational studies showed similar results; pooled RR $(95 \% \mathrm{Cl}) 1.16(1.05,1.29), \mathrm{I}^{2}=69 \%$.

Sensitivity analysis excluding the study by Kim et al again showed significantly higher en bloc resection rate with UEMR; pooled RR $(95 \% \mathrm{Cl}) 1.13(1.04,1.22)$ and heterogeneity decreased substantially $\left(I^{2}=0 \%\right)$. Sensitivity analysis by excluding one study [15] where mean polyp size in the EMR group (30 $\mathrm{mm}$ ) was larger than UEMR group $(20 \mathrm{~mm})$ also showed consistent results, Pooled RR $(95 \% \mathrm{Cl}) 1.15(1.06,1.25)$.

\section{Recurrent/residual polyps}

Three observational studies $[9,14,15]$ reported data on recurrent/residual polyps on follow-up colonoscopy. One hundred two polyps had been removed by UEMR and 190 by EMR. At surveillance colonoscopy, rates of recurrent/residual polyps with UEMR and EMR were $7 \%$ and $22 \%$, respectively. Pooled analysis showed that recurrent/residual polyps were less likely to be seen after UEMR; pooled RR $(95 \% \mathrm{Cl}) 0.26(0.12,0.56), \mathrm{I}^{2}=0 \%$ ( Fig.2b) and this analysis reached statistical significance. Sensitivity analysis by excluding one study [15] where mean polyp size in the EMR group $(30 \mathrm{~mm})$ was larger than in the UEMR group $(20 \mathrm{~mm})$ also showed consistent results; pooled $\operatorname{RR}(95 \% \mathrm{Cl}) 0.26(0.11,0.59), \mathrm{I}^{2}=0 \%$

\section{Complete macroscopic resection}

Three observational studies $[9,14,15]$ reported data on complete macroscopic resection with 159 polyps resected by UEMR and 218 by EMR. UEMR was associated with a statistically significant higher rate of complete macroscopic resection compared to EMR; pooled RR (95\% Cl) 1.28 (1.18, 1.39), I²=94\% ( $\triangleright$ Fig.3a). Sensitivity analysis by excluding the study by Kim et al also showed a significantly higher rate of complete macroscopic resection with UEMR compared to EMR, pooled RR (95\% 


\begin{tabular}{|c|c|c|c|c|c|c|c|c|c|c|}
\hline Study or subgroup & \multicolumn{2}{|c|}{ UEMR } & $\begin{array}{r}\text { EI } \\
\text { Events }\end{array}$ & $\begin{array}{l}\text { MR } \\
\text { Total }\end{array}$ & Weight & $\begin{array}{c}\text { Risk ratio } \\
\text { M-H, fixed, } 95 \% \mathrm{CI}\end{array}$ & Year & \multicolumn{2}{|c|}{$\begin{array}{c}\text { Risk ratio } \\
\text { M-H, fixed, } 95 \% \mathrm{Cl}\end{array}$} & \\
\hline Kim et al, 2014 & 32 & 36 & 14 & 44 & $9.4 \%$ & $2.79[1.79,4.37]$ & 2014 & & & \\
\hline Schenck et al, 2017 & 72 & 73 & 54 & 62 & $43.7 \%$ & $1.13[1.03,1.25]$ & 2017 & & - & \\
\hline Rodriguez-Sanchez et al, 2019 & 950 & 50 & 100 & 112 & $46.8 \%$ & $1.11[1.04,1.19]$ & 2019 & & - & \\
\hline Total $(95 \% \mathrm{Cl})$ & & 159 & & 218 & $100.0 \%$ & $1.28[1.18,1.39]$ & & & 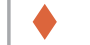 & \\
\hline Total events & 154 & & 168 & & & & & & & \\
\hline $\begin{array}{l}\text { Heterogeneity: } \mathrm{Chi}^{2}=32.58, \mathrm{~d} \\
\text { Test for overall effect: } \mathrm{Z}=6.00\end{array}$ & $\begin{array}{l}\mathrm{df}=2(P \\
0(P=0 .\end{array}$ & $\begin{array}{l}0.00 \\
00001\end{array}$ & $001) ; 1^{2}=$ & $=94 \%$ & & & 0.2 & $\begin{array}{l}0.5 \\
\text { Favours [EMR] }\end{array}$ & 1 Favour & $\begin{array}{l}2 \\
\text { s [UEMR] }\end{array}$ \\
\hline
\end{tabular}

a Forest plot to compare complete macrosopic resesction rate between UEMR and EMR

\begin{tabular}{|c|c|c|c|c|c|c|c|c|c|}
\hline \multirow[b]{2}{*}{ Study or subgroup } & \multicolumn{2}{|c|}{ UEMR } & \multicolumn{2}{|c|}{ EMR } & \multicolumn{2}{|r|}{ Risk ratio (non-event) } & \multicolumn{2}{|c|}{ Risk ratio (non-event) } & \\
\hline & & Total & Events & Total & Weight & M-H, fixed, 95\% Cl & M-H, fixec & & \\
\hline Cadoni, 2017 & 56 & 81 & 51 & 77 & $33.5 \%$ & $0.91[0.58,1.44]$ & 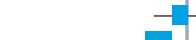 & & \\
\hline Yamashina et al, 2019 & 74 & 108 & 51 & 102 & $65.8 \%$ & $0.63[0.45,0.88]$ & & & \\
\hline Yen et al, 2019 & 66 & 68 & 50 & 50 & $0.7 \%$ & $3.70[0.18,75.33]$ & & & \\
\hline Total (95\% CI) & & 257 & & 229 & $100.0 \%$ & $0.75[0.57,0.98]$ & $>$ & & \\
\hline Total events & 196 & & 152 & & & & & & \\
\hline Heterogeneity: Chi $^{2}=2$ & $2, d f=2($ & $P=0.2$ & ); $1^{2}=2$ & & & & & & \\
\hline Test for overall effect: Z & $2.13(P=$ & $0.03)$ & & esctio & ate bety & UEMR and EMR & $\begin{array}{c}0.1 \\
\text { Favours [UEMR] }\end{array}$ & $\begin{array}{r}10 \\
\text { Favours [EMR] }\end{array}$ & 100 \\
\hline
\end{tabular}

- Fig. 3 Forest plot to compare complete macroscopic resection and histologic resection rate between UEMR and EMR.

Cl) $1.12(1.06,1.19)$ and heterogeneity decreased substantially $\left(I^{2}=0 \%\right)$.

\section{Complete resection confirmed by histology}

Three studies (2 RCTs and 1 observational study) [11-13] reported data on this outcome and showed superiority of UEMR which reached statistical significance; Pooled RR $(95 \% \mathrm{Cl}) 0.75$ $[0.57,0.98]$, Cochran $Q$ test $P=0.24, I^{2}=29 \%$ ( Fig. 3b). Analysis of RCTs only showed similar results; pooled RR $(95 \% \mathrm{Cl}) 0.66$ $(0.47,0.93)$, Cochran $Q$ test $P=0.25, I^{2}=25 \%$

\section{Adverse events}

Seven studies (2 RCTs and 5 observational) reported data on AEs. Immediate post-polypectomy bleeding (IPPB) requiring endoscopic therapy and delayed post-polypectomy bleeding (DPPB) were the most common AEs occurring with $5.5 \%$ and $1.5 \%$ of polypectomies, respectively. There were no statistically significant differences in the rates of AEs between the two techniques; pooled RR $(95 \% \mathrm{Cl})$ was $0.68(0.44,1.05), \mathrm{I}^{2}=17 \%$ ( Fig.4). Subgroup analysis including RCTs only was consistent; pooled RR $(95 \% \mathrm{Cl}) 1.30(0.44,3.86), \mathrm{I}^{2}=0 \%$. Sensitivity analysis by excluding the study by Kim et al showed similar results; pooled RR (95\% Cl) 0.70 (0.46, 1.09), $I^{2}=26 \%$.

Subgroup analysis based on type of adverse events showed a significantly lower rate of IPPB following UEMR; pooled RR (95\% $\mathrm{Cl}$ ) was $0.60(0.36,0.99), \mathrm{I}^{2}=11 \%$. There was no significant difference in the rate of DPPB between the two techniques; pooled RR $(95 \% \mathrm{Cl})$ was $1.07(0.43,2.70), \mathrm{I}^{2}=0 \%$. There was one case of perforation with each technique.

\section{Discussion}

During the last several decades, EMR has been the treatment modality of choice for managing sessile colorectal polyps over $10 \mathrm{~mm}$ in diameter. However, the rate of en bloc resection decreases with increase in polyp size over $10 \mathrm{~mm}$ [17] and practice guidelines recommend that en bloc resection be limited to lesions $\leq 20 \mathrm{~mm}$ in the colon. UEMR, a newer technique first described in 2012 [7], is gaining popularity for the management of large sessile colorectal polyps. UEMR eliminates submucosal injection prior to EMR based on the rationale that the anti-gravity "floating" effect of water immersion on the mucosa and submucosa relative to the muscularis layer, in addition to preservation of wall thickness in a non-distended lumen, makes this step unnecessary. Advantages of eliminating submucosal injection are avoidance of displacement or distortion of the polyp anatomy that may make resection more difficult, avoidance of bleeding from needle puncture, and avoidance of the risk of dysplastic or neoplastic cell seeding. Thermal injury to deeper wall layers may be decreased due to the heat-sink effect of water submersion. Successful resection of polyps refractory to EMR due to scarring after prior attempted resection or instrumentation has been reported with UEMR [7]. Comparative studies had reported conflicting results thereby justifying this systematic review and meta-analysis.

We found that UEMR was associated with a significantly higher en bloc resection rate than EMR. Results were similar in subgroup analyses including RCTs only and on sensitivity analyses. This is clinically important since the incomplete resection of sessile colorectal polyps is associated with>15\% local recur- 


\begin{tabular}{|c|c|c|c|c|c|c|c|c|c|c|}
\hline \multirow[b]{2}{*}{ Study or subgroup } & \multicolumn{2}{|c|}{ UEMR } & \multicolumn{2}{|c|}{ EMR } & \multirow[b]{2}{*}{ Weight } & \multicolumn{2}{|l|}{ Risk ratio } & \multirow{2}{*}{\multicolumn{2}{|c|}{$\begin{array}{c}\text { Risk ratio } \\
\text { M-H, fixed, } 95 \% \mathrm{Cl}\end{array}$}} & \\
\hline & vents & Total & Events & Total & & M-H, fixed, $95 \% \mathrm{Cl}$ & & & & \\
\hline \multicolumn{11}{|l|}{ 1.5.1 RCTs } \\
\hline Yamashina et al, 2019 & 3 & 108 & 2 & 102 & $4.3 \%$ & $1.42[0.24,8.31]$ & & & $\square$ & \\
\hline Yen et al, 2019 & 5 & 68 & 3 & 50 & $7.1 \%$ & $1.23[0.31,4.89]$ & & & & \\
\hline Subtotal $(95 \% \mathrm{Cl})$ & & 176 & & 152 & $11.4 \%$ & $1.30[0.44,3.86]$ & & & & \\
\hline Total events & 8 & & 5 & & & & & & & \\
\hline \multicolumn{11}{|c|}{ Heterogeneity: $\mathrm{Chi}^{2}=0.02, \mathrm{df}=1(P=0.90) ; \mathrm{I}^{2}=0 \%$} \\
\hline \multicolumn{11}{|c|}{ Test for overall effect: $Z=0.47(P=0.64)$} \\
\hline \multicolumn{11}{|l|}{ 1.5.2 Observational } \\
\hline Cadoni, 2017 & 11 & 81 & 11 & 77 & $23.3 \%$ & $0.95[0.44,2.06]$ & & & & \\
\hline Chien et al, 2019 & 10 & 121 & 22 & 121 & $45.5 \%$ & $0.45[0.22,0.92]$ & & - & & \\
\hline Kim et al, 2014 & 0 & 36 & 2 & 44 & $4.7 \%$ & $0.24[0.01,4.91]$ & & & & \\
\hline Rodriguez-Sanchez et al, 201 & 91 & 50 & 11 & 112 & $14.0 \%$ & $0.20[0.03,1.53]$ & & & - & \\
\hline Schenk et al, 2017 & 3 & 73 & 0 & 62 & $1.1 \%$ & $5.96[0.31,113.19]$ & & & & $\rightarrow$ \\
\hline Subtotal $(95 \% \mathrm{Cl})$ & & 361 & & 416 & $88.6 \%$ & $0.60[0.38,0.97]$ & & & & \\
\hline Total events & 25 & & 46 & & & & & & & \\
\hline \multicolumn{11}{|c|}{ Heterogeneity: Chi $^{2}=5.73, \mathrm{df}=4(P=0.22) ; \mathrm{I}^{2}=30 \%$} \\
\hline \multicolumn{11}{|c|}{ Test for overall effect: $Z=2.10(P=0.04)$} \\
\hline Total $(95 \% \mathrm{Cl})$ & & 537 & & 568 & $100.0 \%$ & $0.68[0.44,1.05]$ & & & & \\
\hline Total events & 33 & & 51 & & & & & & & \\
\hline \multicolumn{11}{|c|}{ Heterogeneity: $\mathrm{Chi}^{2}=7.24, \mathrm{df}=6(P=0.30) ; I^{2}=17 \%$} \\
\hline \multicolumn{7}{|c|}{ Test for overall effect: $Z=1.75(P=0.08)$} & 0.01 & 0.1 & 10 & 100 \\
\hline \multicolumn{7}{|c|}{ Test for subgroup differences: $\mathrm{Chi}^{2}=1.59, \mathrm{df}=1(P=0.21), \mathrm{I}^{2}=37.3 \%$} & & Favours [UEMR] & Favours [EMR] & \\
\hline
\end{tabular}

rence rates [18] necessitating more frequent surveillance colonoscopies and increasing the risk of interval cancer development. This analysis, however, was limited by moderate heterogeneity $\left(1^{2}=49 \%\right)$ which may be due to difference in polyp sizes and possibly different locations. We addressed this issue by performing a sensitivity analysis which led to substantial decrease in heterogeneity $\left(\mathrm{I}^{2}=0 \%\right)$. Another limitation of this analysis is the small number of RCTs (only two) in the subgroup analysis. This number is too small to make any firm conclusions. These limitations limit the validity of our results and more RCTs are warranted to further evaluate the possible superiority of UEMR in achieving a higher en bloc resection rate compared to EMR.

Consistent with the higher rate of en bloc resection, UEMR was also associated with significantly reduced rates of residual or recurrent polyps seen at surveillance colonoscopy. Reported polyp recurrence rates after EMR can be as high as $15 \%$ to $50 \%$ $[19,20]$. A subgroup analysis based on fully published articles in peer-reviewed journals confirmed that UEMR led to lower rates of residual or recurrent polyps. However, the analysis of "recurrent or residual polyps" included only three studies and is underpowered to make any firm conclusions.

UEMR was associated with significantly less IPPB that required endoscopic therapy. Otherwise, we found no significant differences in the occurrence of adverse events between the two techniques. It is not entirely clear why UEMR should be associated with less IPPB. One possible explanation is that UEMR produces a smaller mucosal defect than EMR. In EMR, the submucosal injection causes the borders of polyps to expand, thereby producing a larger defect after snare resection. In UEMR, floating of mucosa and submucosa over muscularis layer leads to a change in shape of lesions and some flat and sessile lesions become smaller and more polypoid in configuration [11]. Resection of such lesions leads to smaller defects. Some studies have shown that fewer clips are required after UEMR than EMR [13], supporting this hypothesis.

This is the first systematic review and meta-analysis to compare the efficacy and safety of UEMR with EMR. Our comprehensive literature search identified a large number of relevant studies. Our analyses may have been weakened by the inherent limitations of meta-analyses and of the individual included studies, most of which were observational. Due to differences in methodology, combining RCTs and observational studies in a meta-analysis may raise the issue of validity of results. Lack of randomization in observational studies, which is necessary to control measured and unmeasured confounding, can affect the validity of study results [21]. To address this issue, we performed predetermined subgroup analyses based on types of studies (i.e., RCTs vs observational) and noticed no difference in results. In addition, we also performed sensitivity analyses by excluding some observational studies that were considered to be outliers (had substantial differences from other studies) with no change in results.

There was significant heterogeneity in the analysis for some outcomes. However, we were able to address this by performing sensitivity analyses. Most of the studies included had one or two operators. A formal propensity score matching was not done in most of the studies, which can possibly affect the out- 
comes due to differences between groups. However, some important parameters such as polyp sizes were comparable between the two groups, as is evident from $>$ Table 2, except for one study [15] where mean polyp size in the EMR group $(30 \mathrm{~mm})$ was larger than in the UEMR group $(20 \mathrm{~mm})$. We performed sensitivity analysis by excluding that study with no change in results.

We could not evaluate the difference in time required by both procedures as studies had not presented adequate data for such analysis. Finally, analyses of some of the outcomes such as "recurrent or residual polyps", "complete macroscopic resection" and "complete resection confirmed by histology" included only three studies each so these analyses are not sufficiently powered to make definite conclusions. Consequently, more studies are required to evaluate these outcomes.

\section{Conclusion}

In summary, UEMR was associated with significantly higher en bloc resection rates than EMR and with lower rates of recurrence and IPPB. If confirmed in randomized controlled trials, UEMR is likely to disseminate as the approach of choice for the resection of large colorectal polyps.

Competing interests

The authors declare that they have no conflict of interest.

\section{References}

[1] Zauber AG, Winawer S], O’Brien M] et al. Colonoscopic polypectomy and long-term prevention of colorectal-cancer deaths. N Engl J Med 2012; 366: 687-696

[2] Kobayashi N, Yoshitake N, Hirahara Y et al. Matched case-control study comparing endoscopic submucosal dissection and endoscopic mucosal resection for colorectal tumors. J Gastroenterol Hepatol 2012; 27: 728-733

[3] Ahlenstiel G, Hourigan LF, Brown G et al. Actual endoscopic versus predicted surgical mortality for treatment of advanced mucosal neoplasia of the colon. Gastrointest Endosc 2014; 80: 668-676

[4] Jayanna M, Burgess NG, Singh R et al. Cost analysis of endoscopic mucosal resection vs surgery for large laterally spreading colorectal lesions. Clin Gastroenterol Hepatol 2016; 14: 271-278 e1-2

[5] Binmoeller KF, Hashimoto Y, Shah JN et al. “Underwater” EMR (UEMR) without submucosal injection for large sessile polyps. Gastrointest Endosc 2012; 75: AB108-AB109
[6] Hwang JH, Konda V et al. ASGE Technical Committee. Endoscopic mucosal resection. Gastrointest Endosc 2015; 82: 215-226

[7] Binmoeller KF, Weilert F, Shah J et al. "Underwater" EMR without submucosal injection for large sessile colorectal polyps (with video). Gastrointest Endosc 2012; 75: 1086-1091

[8] Spadaccini M, Fuccio L, Lamonaca L et al. Underwater EMR for colorectal lesions: a systematic review with meta-analysis (with video). Gastrointest Endosc 2019; 89: 1109-1116 e4

[9] Kim HG, Thosani N, Banerjee S et al. Underwater endoscopic mucosal resection for recurrences after previous piecemeal resection of colorectal polyps (with video). Gastrointest Endosc 2014; 80: 1094-1102

[10] Liberati A, Altman DG, Tetzlaff ] et al. The PRISMA statement for reporting systematic reviews and meta-analyses of studies that evaluate healthcare interventions: explanation and elaboration. BMJ 2009; 339: b2700

[11] Yamashina T, Uedo N, Akasaka T et al. Comparison of underwater vs conventional endoscopic mucosal resection of intermediate-size colorectal polyps. Gastroenterology 2019; 157: 451-461.e2

[12] Cadoni S, Liggi M, Gallittu P et al. Underwater endoscopic colorectal polyp resection: Feasibility in everyday clinical practice. United European Gastroenterol J 2018; 6: 454-462

[13] Yen AW, Leung JW, Wilson MD et al. Underwater versus conventional endoscopic resection of nondiminutive nonpedunculated colorectal lesions: a prospective randomized controlled trial (with video). Gastrointest Endosc 2020; 3: 643-654

[14] Schenck RJ, Jahann DA, Patrie JT et al. Underwater endoscopic mucosal resection is associated with fewer recurrences and earlier curative resections compared to conventional endoscopic mucosal resection for large colorectal polyps. Surg Endosc 2017; 31: 4174-4183

[15] Rodriguez Sanchez], Uchima KoecklinH, Gonzalez LopezL et al. Short and long-term outcomes of underwater EMR compared to the traditional procedure in the real clinical practice. Rev Esp Enferm Dig 2019; 111: 543-549

[16] Chien HC, Uedo N, Hsieh PH. Comparison of underwater and conventional endoscopic mucosal resection for removing sessile colorectal polyps: a propensity-score matched cohort study. Endosc Int Open 2019; 7: E1528-e1536

[17] Hurlstone DP, Sanders DS, Cross SS et al. Colonoscopic resection of lateral spreading tumours: a prospective analysis of endoscopic mucosal resection. Gut 2004; 53: 1334-1339

[18] Hotta K, Fujii T, Saito Y et al. Local recurrence after endoscopic resection of colorectal tumors. Int J Colorectal Dis 2009; 24: 225-230

[19] Khashab M, Eid E, Rusche M et al. Incidence and predictors of "late" recurrences after endoscopic piecemeal resection of large sessile adenomas. Gastrointest Endosc 2009; 70: 344-349

[20] Belderbos TD, Leenders M, Moons LM et al. Local recurrence after endoscopic mucosal resection of nonpedunculated colorectal lesions: systematic review and meta-analysis. Endoscopy 2014; 46: 388-402

[21] Sorensen HT, Lash TL, Rothman KJ. Beyond randomized controlled trials: a critical comparison of trials with nonrandomized studies. Hepatology 2006; 44: 1075-1082 